\title{
A CRITICAL ANALYSIS OF SOFTWARE FAILURE CAUSES FROM PROJECT MANAGEMENT PERSPECTIVES
}

\author{
Amjad Hussain Zahid ${ }^{1}$, M. Waji Haider, Muhammad Shoaib FarooQ, Adnan ABID, AmJad Ali \\ Department of Computer Science, University of Management And Technology, Lahore, Pakistan \\ Email:1amjad.zahid@umt.edu.pk
}

\begin{abstract}
With the growth of technology, people and companies are more relying on software systems. For that, we need a product/software that is trustworthy, reliable, and economical. It should be maintainable, dependable and useable. If the software is developed with much accuracy, everything is being done by it as planned and the software is set to the market then the success rate will be high. But if there is any bug in the software then not only the software will fail but it will also affect the organizations that are responsible for making it. So the failure of software also has a great impact on the organization. In this research, we are going to present a detailed and critical analysis of all those causes due to which the software fails and the factors that hinder in a project success. We will study the existing software development processes and also analyze how they can helpful in reducing these causes.
\end{abstract}

Keywords:Software Projects, Failure Factors, Project Failure, Critical Analysis

1.Introduction. When software is being developed it has to pass through following steps; Communication, planning, modeling, construction, and deployment. These following steps are used to all software's development. The first phase of software development is communication in which the Requirement engineer which has been appointed for the development of the software needs to gather requirements from the client/customer so that they can know what the client wants in the software.

The client sometimes failed to provide the exact requirements to the requirement engineer or the person who is gathering the requirements from the client either have too much to convey or he is unable to understand the minimal requirements of the customer which leads the software to failure. After all the phases are clearly defined then comes the deployment phase which is the last phase in any software development. In this phase the software which has been developed is handed over to the client who checks the software and uses it. If the software is as according to the clients requirement then the software is passed and the organization will be getting a good feedback from the client but if the software doesn't perform exactly as the client's desire then the software fails and it will give feedback to the organization which will cause the reputation of the organization. If the feedback is good then the reputation will be good otherwise it will be bad

When software fails it not only affects the client but also the organization which was responsible for the development of that particular software which has been failed to make the work of a client into a total mess. The failure of software can also exploit economic growth and quality of life.

Factors which can make software to fail are unrealistic project goals, inaccurate estimation of resources, badly or poorly defined requirements, unmanaged risks, poor communication between customers, users and developers, poor project management, stakeholder politics, commercial pressure. These are most common factors which can make software not to work properly. We have mostly listened to the clients that my system got down or the software has crashed, why these issues come. This is because that the software which is being used had some missing loops in it which causes these types of issues. The sooner the error is caught the better it is to fix it otherwise once it is in the market then there is no turning back.

The organizational structure and their budget and resources are very important. There is a great pressure of upper-level management on the development team and project managers. The pressure affects the performance of the team which has a bad effect on the project. These are the useful factors which if not properly handled can cause the software to fail resulting the reputation of the software house. If the software is 
developed with good quality and there is no delayed in the project but the software doesn't provide the desired functionality as expected then the software is useless whether it is good or not. The basic aim is on the functionality of the software that how it is performed and what can it do.

There are many factors which have a great impact on the success and failure of any software system by both perspectives, negatively and positively. It is very important to clearly identify all of those factors that are involved in a project failure. It is the need of the time to know the causes for software project failure so that one can be able to avoid or manage all the causes in an effective and efficient way and the reputation of the organization can be positive. So reputation of the organization it is based on the software success.

The goal of this paper is to identify the main causes due to which a software system fails in the software industry. We need to locate the causes of why a software system is failed and also discuss that how we can overcome these issue and causes by using an existing software development model.

2.Literature Review:Authors [1] describe that there are personality checks in the project which can cause failure in the project. When a project is being made the team members are sometimes not playing their part which can cause clashes in the team and can affect the overall project.

Due to the software failure the client is not happy as well as it affects the organization [2]. 70 failed projects were analyzed and by that study, it was purposed that most of the software projects were failed due to the numerous factors.

Authors [3] present a detailed study of the failure of software projects. They said that the organizational structure and their budget and resources are very important. There is a great pressure of upper-level management on the development team and project managers. The pressure affects the performance of the team which has a bad effect on the project. Paul Dorsey et al [4] define the reason of software failure. He explains that software project frequently failed as they are not $100 \%$ perfect. The failure rate of software projects is reported between $50 \%-80 \%$.

In the field of software development, it is seen that failure can occur [5]. Although the actions have done to make the software projects according to the rules and book so where is the error in it? Authors discuss the primary cause of the failure in the software projects. Nowadays most of the organizations are doing agile development in the field of software which uses different models for the development purpose so that the software can be developed step by step and each phase should be will define and developed. It was found that over 50,000 IT projects, only $29 \%$ are those which have been a success [5].

Peter Henderson et al [6] discuss the failure of large software projects. Mostly the reason behind the failure is over budget or when it is delivered to the client it is not what the client has wished for or what the client actually needed. Some of the software fails which contains a large number of employees for the development of that particular software and it takes a lot of time to complete as well. It's not about the number of employees it about how much knowledge and skills an employee has about the development of that software. Kaur et al [7] explain briefly that in the development of a software we use some process models and each process model which is implemented manages various concerns related to cost, time, quality and client's requirements. The causes which are described in [7] are the identified estimation mistakes, unclear project goals, and objectives, changing of project requirement during the project. A client has given the project idea to the development team and also described the requirement specifications to the project manager.

Authors [8] studied different companies and come up with a fact that most of the companies failed software projects due to time and budget factors. Some of them are canceled before the completion of the project. The most common cause of software project failure is due to poor project management. Factors which are involved in the failure of the software projects are poor planning, unclear objectives and goals; objectives change during the project, unrealistic time or resource estimate, lack of user involvement and executive support, failure to communicate and act as a team and inappropriate skills.

Richard et al [9] discussed the success of software. The qualities which successful projects have are meeting business goals; deliver on time, complete in a budget and meeting the customer requirements. If these requirements are not followed as described then the software tends to fail. According to this research, it is found that $61.5 \%$ of software projects over time estimate, over budget and has fewer functionalities and features and for this, the main reason which causes software project to fail is poor management.

3.Research Objectives:We face many problems during the development of a software project. There are many factors that count too much in the failure and success of software projects. If we try to avoid or overcome those causes then the failure ratio of the software system can be decreased to some extent causing a good repute to the 
organization. The objectives of our research are:

- To do a critical analysis of those causes and give reasons due to which most organizations move towards the failure. We will also focus on those causes that how they affect a software system which can cause organizations to have a bad repute.

- $\quad$ To study and identify the best software development model from the existing ones which can help to overcome the causes of software failure making the status of the organization high which is responsible for making that specific software.

4. Research Questions:We have addressed the following questions:

- What are the main reasons and causes due to which the software fails?

- Can involvement of the client cause failure in the development of the software?

5.Information Collection:Information collection or data collection is the far most important part in the research. Due to this phase we are able to find the views of people working in a software houses and how software can fail or what are the factors affecting the software failure. We have collected data from Pakistan 26 software houses. We have targeted the people which include developers, QA analyst, Requirement engineers, software engineers, software developers and project managers.

We have analyzed the data by providing the questionnaires to the people and they have selected the options that are suitable according to them. This survey was for Pakistan software houses and by this analyzes we have seen the features that are important for software project success and can minimize the failure of software. We need to meet these parameters for success of the project as these parameters identify the problems for software failure.

We have been able to gathered data from Web developers, QA analyst, Requirement engineer, Software developer, Software Engineer, Project managers, Business analyst as shown in figure 1. It is very important to select the audience from which you need to get the views about a specific product. These people have been involved with the type of issues so their feedback counts.

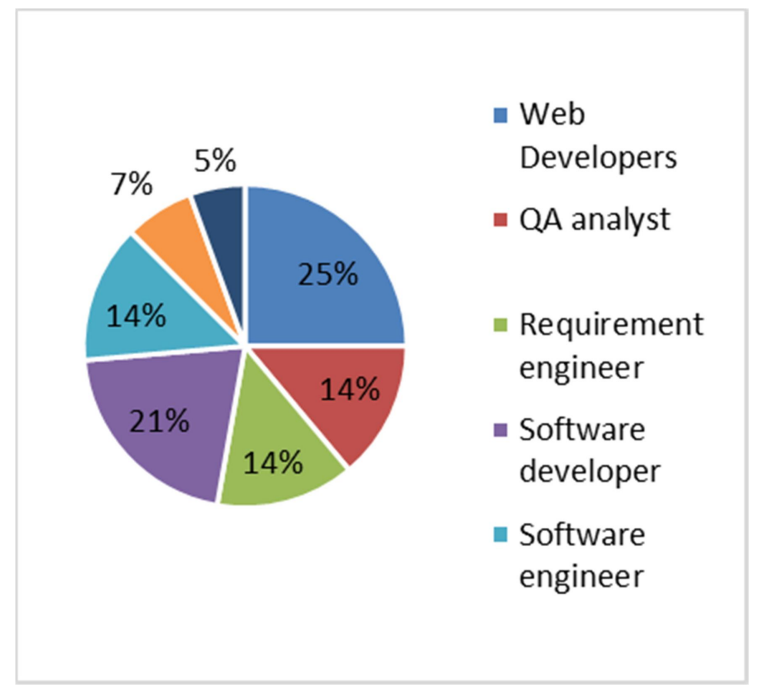

Figure 1:Questionnaire Sources

We have gathered information on what type of projects are developing in different software houses. Most of the software houses follow these techniques which I have mentioned in the paper to avoid the failure of the software. The projects which are being developed include Web applications, theme development, Ecommerce sites, Mobile applications and Game development as shown in figure 2. 


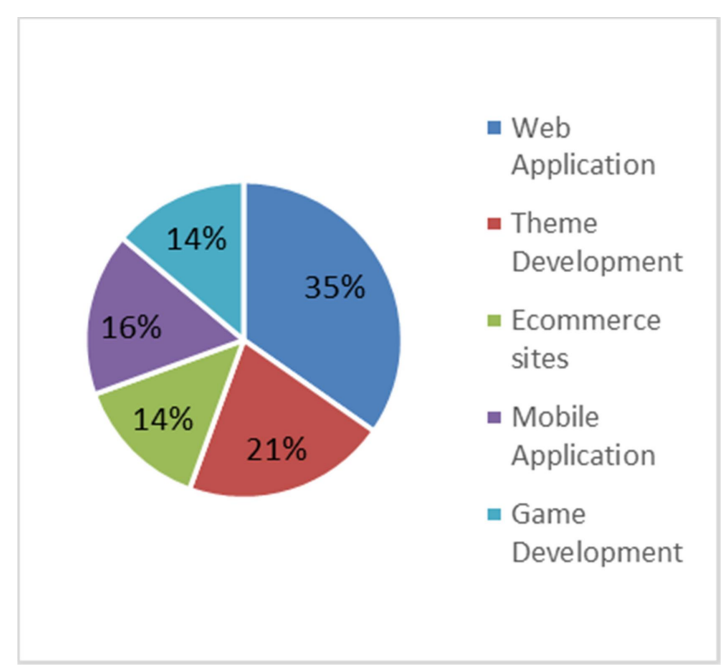

Figure 2: Projects in Software Houses

There are a lot of problems which have been identified in the field of software developments but the main issue which most of the users agree on is that Lack of access to end users is a big reason in the failure of software projects. From the graph it is seen that most of the people strongly agreed on this problem as seen in figure 3 .

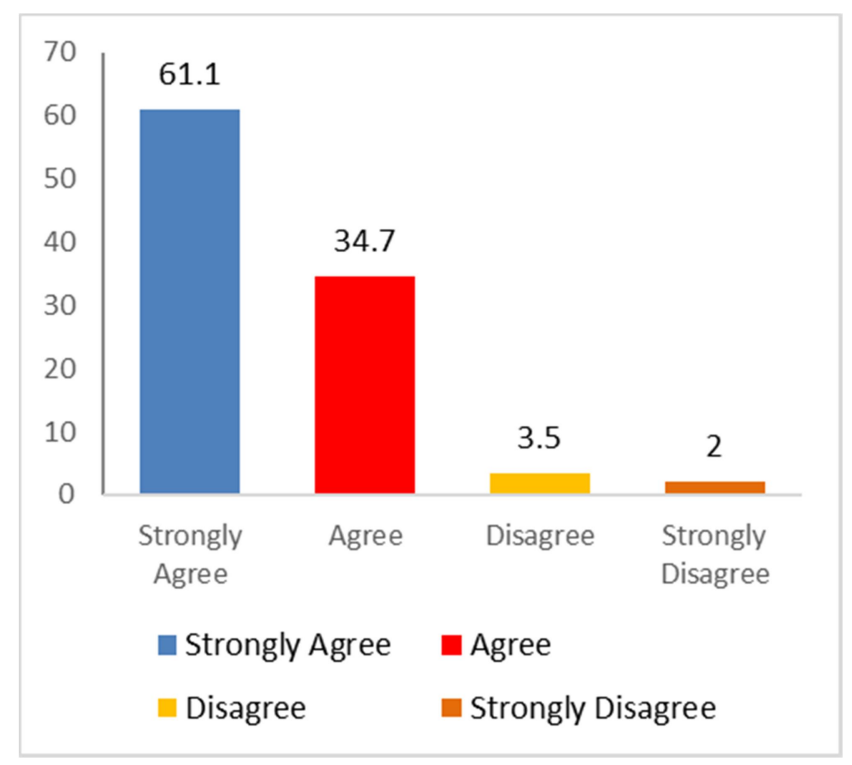

Figure 3:Lack of access to end-users

The next problem which is mostly seen is the major reason for project failure is the change of project scope during the projects process. Yes it is a big issue as this problem can cause the project to get late resulting in the failure of the software as seen in figure 4. 


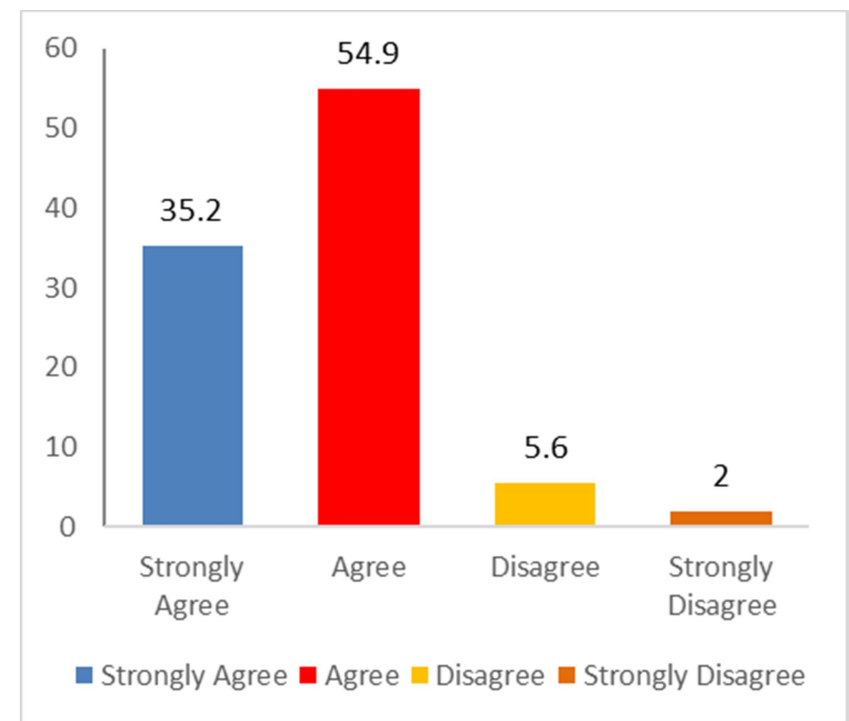

Figure 4: Change of project scope duringthe project's process.

Table 1: Lack of access to end-users is a big reason for the failure of software project

\begin{tabular}{|c|c|c|}
\hline & Frequency & Percent \\
\hline Strongly Agree & 44 & 61.1 \\
\hline Agree & 25 & 34.7 \\
\hline Disagree & 3 & 4.2 \\
\hline Total & 72 & 100.0 \\
\hline
\end{tabular}

Table 2:The major reason for project failures is the change of project scope during the project's process

\begin{tabular}{|c|c|c|}
\hline & Frequency & Percent \\
\hline Strongly Agree & 40 & 55.6 \\
\hline Agree & 25 & 34.7 \\
\hline Disagree & 4 & 5.6 \\
\hline Strongly Disagree & 3 & 4.2 \\
\hline Total & 72 & 100.0 \\
\hline
\end{tabular}

In the following figure 5, we have stated some causes of software failure in software industry which we analyzed from our research and study. 


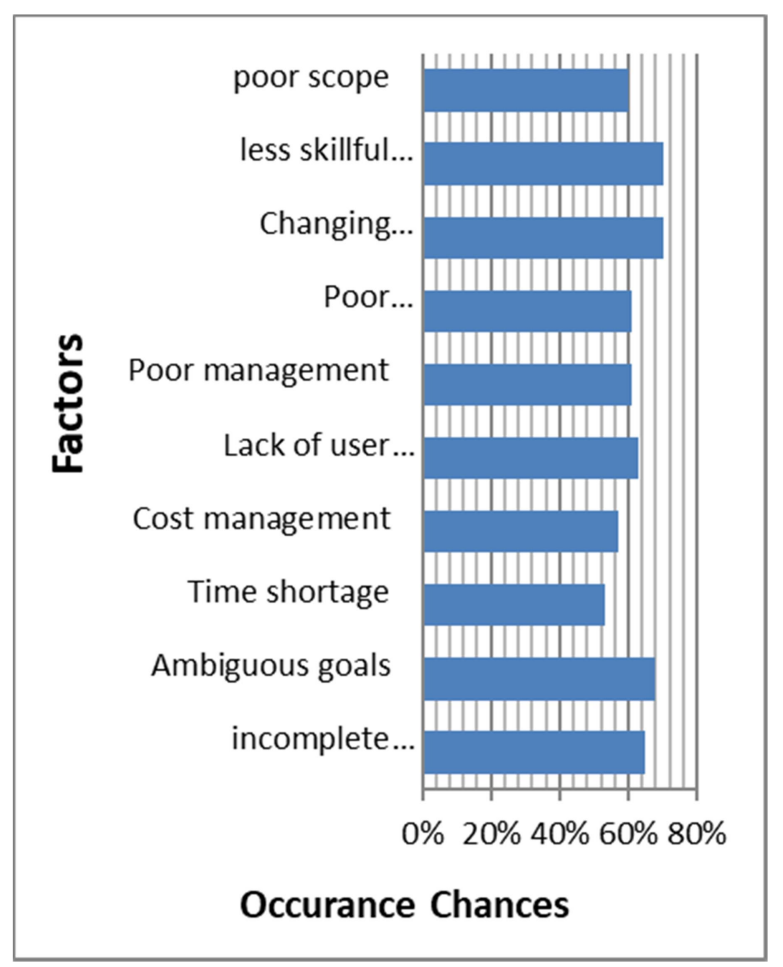

Figure 5:Causes of software failure

6.Discussion And Future Work:The identification of main reasons and causes that are hurdles to reputation of the software house are totally dependable on the success of a software system which will be the major outcome of this research. In our research, we have also provided the feedback of different employs working in a software houses and their reviews about the failure of software and what are the major aspects which causes software to fail. Moreover we have also explained some factors which have been affecting the software to fail. Our future work will be that we will be minimizing the faults and errors, factors which cause software to fail so that the software can be a success for both the client and the organization.

Moreover we have also explained some factors which have been affecting the software to fail. These factors include incomplete requirements, Ambiguous goals, time shortage, cost management, lack of user involvement during the development all these are the issue which can affect a software and if treated and kept them in mind then the software can be a success otherwise it will fail and when a software fails it not only affect the client or the developer but it also effect the overall organizing who's employees have developed it. The reputation of the organization is very important.

Software development is a very vast field in which software need to pass through different process till it finishes. The software development starts by gathering requirements form the client in which the requirement engineer and the client communicate with each other and specify a requirement document. After the requirements have been gathered it is passed through different process in which the development takes place according to the document which was created at the start till the deployment. If the software is developed according to the clients provided requirements then the software is success otherwise it fails.

Many researchers have proposed their research on this issue and given some solutions which can minimize the risk of the software failure. Most of the researchers have pointed the main issue of failure that is gathering of requirements. If the process of gathering requirement performs properly and efficiently, then all other tasks will be performed accurately. But if that first and primary phase is full of errors and ambiguity then all other phase will be affected by it.

In Pakistan software industry there are many limitations in the development of software development. We have done survey in 14 to 15 different software houses of Pakistan. In our thesis we do detailed study about the software failure in Pakistan software industry. We hope that our work about the issues of analysis of software failure will help the Pakistan software industry in future to implement all its practices in a good and appropriate way. 


\section{REFERENCES}

[1] Charette, R. N. (2005). Why software fails [software failure]. Ieee Spectrum, 42(9), 42-49.

[2] Verner, J., Sampson, J., \& Cerpa, N. (2008, June). What factors lead to software project failure?. In Research Challenges in Information Science, 2008. RCIS 2008. Second International Conference on (pp. 71-80). IEEE.

[3] Agarwal, N., \& Rathod, U. (2006). Defining 'success' for software projects: An exploratory revelation. International journal of project management, 24(4), 358-370.

[4] 'Top 10 reasons why systems projects fail', http://rrsg.ee.uct.ac.za/courses/ EEE4084F/ Archive/2014/Assignments/ReadingAssignments/Lect21Dorsey_Top10ReasonsSystemsProjectsFail.pdf, Retrieved Feb., 10 (2018)

[5] Whitney, K. M., \& Daniels, C. B. (2013). The root cause of failure in complex IT projects: complexity itself. Procedia Computer Science, 20, 325-330.

[6] Henderson, P. (2006). Why large it projects fail. ACM Trans. Program. Lang. Syst, 15(5), 795-825..

[7] Kaur, R., \& Sengupta, J. (2013). Software process models and analysis on failure of software development projects. arXiv preprint arXiv:1306.1068.

[8] Young, S. (2003). Why IT projects fail. Computerworld, 37(34), 44-44.

[9] Berntsson-Svensson, R., \& Aurum, A. (2006, September). Successful software project and products: An empirical investigation. In Proceedings of the 2006 ACM/IEEE international symposium on Empirical software engineering (pp. 144-153). ACM. 